\title{
Analisis Kualitas Website dan Kepuasan Nasabah Terhadap Website PT. Bank Sinarmas Tbk Menggunakan Metode Webqual 4.0
}

\author{
Ade Winarni ${ }^{1}$,Wellian Riska ${ }^{2}$ \\ Sistem Informasi STT Indonesia Tanjungpinang \\ Jln. Pompa Air No.28 Tanjungpinang, Kep.Riau \\ Iadewina16@gmail.com, ${ }^{2}$ kaka.wr16@gmail.com,
}

\begin{abstract}
Intisari-Website memiliki peranan penting bagi perbankan karena merupakan media informasi sekaligus sarana promosi berbasis online yang sangat effective digunakan untuk menjangkau masyarakat luas. PT. Bank Sinarmas Tbk sebagai salah satu bank terbesar di Indonesia tentunya memiliki keperluan untuk memiliki website berkualitas tinggi agar dapat bersaing dengan bank-bank lainnya dalam memberikan layanan informasi terbaik baik untuk nasabah maupun calon nasabanya.

Sayangnya, hingga saat ini masih belum ada pengukuran terkait tingkat kepuasan nasabah terhadap kualitas website yang dimiliki oleh Bank Sinarmas. Mengetahui hal itu maka dilakukan penelitian berjudul "Analisis kualitas website dan kepuasan nasabah terhadap website PT. Bank Sinarmas Tbk menggunakan metode webqual 4.0".

Penelitian dilakukan dengan mengukur tingkat kepuasan nasabah berdasarkan 4 variabel penting yaitu ketergunaan (usability), kualitas informasi (information quality), kualitas layanan interaksi (service interaction quality) dan kepuasan nasabah (service user satisfication). Pada penelitian ini akan dianalisis data dari jawaban kuesioner yang telah dibagikan kepada 50 sampel random nasabah PT. Bank Sinarmas, Tbk kantor cabang Tanjungpinang menggunakan metode Webqual 4.0 dan software SPSS 22.

Kata Kunci : website, kualitas website, pengukuran kualitas website, Bank Sinarmas, kepuasan nasabah, webqual 4.0, SPSS 22
\end{abstract}

Abstract-Website has an important role for banks because it is an information media as well as online-based promotional tool which is very effective to be used to reach the wider community. PT. Bank Sinarmas Tbk as one of the largest banks in Indonesia certainly has the need to have a high-quality website in order to compete with other banks in providing the best information services for customers and prospective clients.

Unfortunately, until now there has been no measurement related to the level of customer satisfaction with the quality of websites owned by Bank Sinarmas. Therefore, a research entitled "Analysis of website quality and customer satisfaction at PT. Bank Sinarmas uses the webqual 4.0 method".

The research was conducted by measuring the level of customer satisfaction based on 4 important variables, such as usability, information quality, service interaction quality and customer satisfaction. In this research will be analyzed from the answers to the questionnaires that have been distributed to 50 random samples of customers of PT. Bank Sinarmas, Tbk Tanjungpinang branch office using Webqual 4.0 method and SPSS 22 software.

Keywords : website, website qualiity, website quality measurement, Bank Sinarmas, customers satisfication, Webqual 4.0, SPSS 22

\section{PENDAHULUAN}

Di era digital saat ini, teknologi informasi merupakan bagian dari kehidupan manusia. Dapat dirasakan peran teknologi kian hari semakin besar karena hampir semua kegiatan bisnis dalam organisasi dapat dilakukan melalui perantara teknologi informasi, salah satunya melalui internet. Internet telah menjadi bagian yang tak dapat terpisahkan dari kehidupan manusia pada saat ini. Dengan menggunakan internet dapat memperoleh berbagai informasi yang dibutuhkan dengan mudah dan juga cepat.

Salah satu pemanfaatan internet yang dapat digunakan dalam memperoleh informasi adalah dengan hadirnya website. Website merupakan sebuah metode untuk menampilkan informasi di internet, baik berupa teks, gambar, suara maupun video yang interaktif dan mempunyai kelebihan untuk menghubungkan (link) satu dokumen dengan dokumen lainnya (hypertext) yang dapat diakses melalui sebuah browser. Website memiliki peran penting bagi sebuah organisasi karena dapat memberikan keuntungan seperti dapat menyediakan pelayanan online bagi para pelanggannya. Salah satu yang menggunakan fasilitas website adalah dari bidang perbankan.

Perkembangan teknologi informasi telah mempengaruhi kebijakan dan strategi dunia usaha perbankan yang selanjutnya lebih mendorong inovasi dan persaingan dibidang layanan. Dengan adanya perpaduan antara teknologi dengan layanan bank tradisional melalui website, menyebabkan penyediaan informasi untuk nasabah tentunya menjadi lebih efektif dan efesien. Selain itu, website pada bank juga dapat digunakan sebagai ajang media promosi atau pemasaran sebuah produk dan jasa bank.

Website yang bagus ialah web yang fokus utamanya adalah isi dari website tersebut, di mana hal itu merupakan faktor utama yang menyebabkan para penggunanya kembali mengunjungi sebuah website. Kualitas website merupakan 
faktor penting yang harus diperhatikan dalam sebuah institusi, hal ini dikarenakan website sebuah institusi merupakan gambaran dari institusi tersebut di dunia maya.

Sejauh ini, layanan website pada bank diimplementasikan belum memiliki cukup bukti yang menyatakan bahwa fasilitas website bank dapat diterima dan dianggap nasabah sebagai salah satu fasilitas yang mampu memberikan kecepatan, ketepatan,dan kenyamanan dalam penyediaan informasi. Oleh karena itu, perlu dilakukan penelitian untuk mengetahui apakah website yang diterapkan sudah mampu memenuhi kriteriakriteria yang diinginkan nasabah baik dari segi kecepatan, ketepatan dan kenyamanan. Perilaku dan reaksi pengguna juga menjadi salah satu faktor untuk mengetahui baik atau tidaknya kualitas fasilitas website. Semakin bagus kualitas website yang disediakan, maka pengguna yaitu nasabah tentunya akan semakin termotivasi untuk terus menggunakan fasilitas website tersebut. Pengukuran kualitas website berdasarkan persepsi dan harapan para penggunanya perlu dilakukan untuk mempertahankan eksistensi dan kesuksesan website tersebut melalui internet.

Menurut Barnes dan Vidgen kualitas website memiliki tiga komponen tolak ukur yaitu usability (kegunaan), information quality (kualitas informasi), dan service interaction quality (kualitas interaksi layanan. Ketiga komponen tersebut merupakan bagian dari komponen yang ada pada metode Webqual yang dapat memberikan informasi yang akurat dan memberikan penilaian terhadap kelayakan suatu website. Dalam pengembangan metode Webqual berdasar pada konsep Quality Function Deployment (QFD) yaitu suatu proses yang berdasar pada "voice of customer". Metode ini sudah banyak digunakan oleh peneliti untuk mengetahui kualitas layanan sebuah website.

PT Bank Sinarmas Tbk adalah Bank Umum Devisa yang didirikan pada tanggal 18 Agustus 1989 dengan nama PT. Bank Shinta Indonesia. Bank memperoleh status sebagai Bank Umum Devisa pada tahun 1995. Kemudian mengalami perubahan nama menjadi PT. Bank Sinarmas pada tahun 2006. PT Bank Sinarmas, Tbk merupakan salah satu bank yang telah menyediakan layanan website kepada nasabahnya, layanan yang disediakan adalah untuk memberikan informasi terkait aktifitas bank seperti informasi produk dan jasa bank saja.

Saat ini belum terdapat pengukuran kualitas pemanfaatan fasilitas website di PT. Bank Sinarmas, Tbk cabang Tanjungpinang. Adapun untuk saat ini yang sudah dilakukan masih sebatas pengukuran terhadap pengaruh kedisiplinan kerja terhadap prestasi kerja karyawan.(Erine Chenmewati, "Analisis Pengaruh Kedisiplinan kerja, Pelatihan, Motivasi dan Lingkungan Kerja Terhadap Prestasi Kerja Karyawan PT. Bank Sinarmas Tbk Cabang Tanjungpinang", Skripsi, 2017). ${ }^{1}$

Berdasarkan uraian di atas, maka penulis tertarik untuk melakukan pennelitian terkait kualitas website dengan judul “Analisis Kualitas Website dan Kepuasan Nasabah Terhadap

${ }^{1}$ Erine Chenmewati, "Analisis Pengaruh Kedisiplinan kerja, Pelatihan, Motivasi dan Lingkungan Kerja Terhadap Prestasi
Website PT Bank Sinarmas Tbk Menggunakan Metode Webqual 4.0".

\section{METODOLOGI PENELITIAN}

\section{A. Studi Pustaka}

Mencari informasi yang berasal dari buku - buku yang berhubungan dengan pengetahuan pengolahan data, akses internet dan metode webqual untuk mencari data data pendukung dari berbagai jurnal dan buku.

\section{B. Observasi, Wawancara \& Kuesioner}

\section{Observasi}

Metode pengumpulan data ini dilakukan dengan melakukan survey langsung ke kantor Bank Sinarmas dan survey terhadap fungsi-fungsi yang ada pada website Bank Sinarmas.

2. Wawancara

Metode pengumpulan data ini dilakukan dengan mengadakan Tanya jawab dan dialog dengan pihak yang berhubungan dengan pemberi pelayanan jasa di PT. Bank Sinarmas, Tbk sehingga mendapatkan informasi yang dibutuhkan.

3. Kuesioner

Metode pengumpulan data ini dilakukan dengan cara memberikan sejumlah pertanyaan dalam bentuk tertulis kepada responden dengan panduan kuesioner. Responden disini merupakan nasabah-nasabah PT. Bank Sinarmas, Tbk.

\section{C. $\quad$ Metode Webqual 4.0}

Metode ini dibagi menjadi beberapa bagian, yaitu :

1. Usability

Usability adalah mutu yang berhubungan dengan rancangan site, sebagai contoh penampilan, kemudahan penggunaan, navigasi dan gambaran yang disampaikan kepada pengguna. Berikut ini tiga komponen umum usability :

1. Adanya keterlibatan seorang pengguna

2. Pengguna melakukan suatu pekerjaan

3. Pengguna melakukan sesuatu dengan adanya produk, sistem atau hal.

2. Information Quality

Kualitas informasi dari penelitian sistem informasi (Information Quality). Information Quality adalah mutu dari isi yang terdapat pada site, pantas tidaknya informasi untuk tujuan pengguna seperti akurasi, format dan keterkaitannya.

3. Service Interaction Quality

Service Interaction Quality adalah mutu dari interaksi

Kerja Karyawan PT. Bank Sinarmas Tbk Cabang Tanjungpinang", Skripsi, 2017 
pelayanan yang dialami oleh pengguna ketika mereka menyelidiki kedalam site lebih dalam, yang terwujud dengan kepercayaan dan empati, sebagai contoh isu dari keamanan transaksi dan informasi, pengantaran produk, personalisasi dan komunikasi dengan pemilik site.

\section{Alur Penelitian}

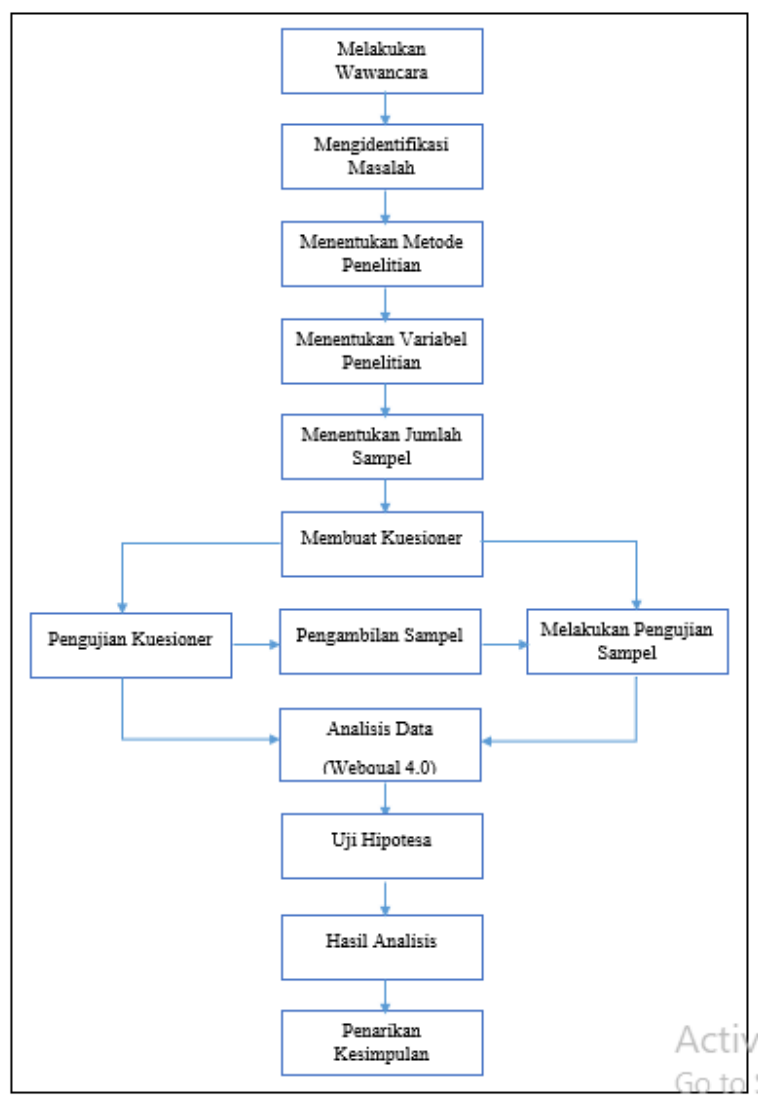

Untuk tahap-tahap pada alur penelitian adalah sebagai berikut

1. Melakukan Wawancara

Penulis melakukan wawancara terhadap pihak Bank untuk menggali informasi yang dibutuhkan seputar penelitian.

2. Mengidentifikasi Masalah

Dari hasil wawancara dan survei maka penulis mengidentifikasi beberapa masalah yang telah disebutkan di Bab I.

3. Menentukan Metode Penelitian Penulis menentukan metode penelitiannya berdasarkan identifikasi masalah yang sudah dtentukan sebelumnya.

4. Menentukan Variabel Penelitian Penentuan variabel penelitian didapat berdasarkan metode Webqual 4.0

5. Menentukan Jumlah Sampel Setelah menentukan variabel penelitian penulis melakukan penentuan jumlah sampel.
6. Membuat Kuesioner

Pembuatan kuesioner juga berasal dari metode Webqual yang sudah disediakan.

7. Pengujian Kuesioner

Kemudian penulis melakukan pengujian pertanyaan

kuesioner apakah valid apa tidaknya suatu pertanyaan.

8. Pengambilan Sampel

Teknik pengambilan sampel penulis melakukan teknik sampling accidental yaitu secara tidak disengaja.

9. Melakukan Pengujian Sampel

10. Analisis Data (Webqual 4.0)

Analisis data menggunakan metode deskriptif dan metode penelitiannya menggunkan metode Webqual 4.0

11. Uji Hipotesa Terdapat beberapa hipotesa yang akan diuji oleh penulis yaitu $\mathrm{H} 1, \mathrm{H} 2, \mathrm{H} 3$ dan $\mathrm{H} 4$

12. Hasil Analisis

Dari semua bagian yang sudah diuji maka akan diketahuilah hasil dari analisis tersebut.

13. Penarikan Kesimpulan

Dari hasil analisis ini penulis akan menarik kesimpulan.

\section{HASIL DAN PEMBAHASAN}

\section{A. Analisis Deskriptif}

Merupakan data atau informasi yang digunakan angket/ kuesioner, kemudian setelah data terkumpul diolah menggunakan IBM SPSS version 22. Selanjutnya untuk mengetahui gambaran masing - masing variabel digunakan analisis deskriptif.

\section{Deskriptif Hasil Penelitian Variabel Usability (X1) \\ Tabel 4.6 Hasil Penelitian Variabel Usability $\left(\mathrm{X}_{1}\right)$}




\begin{tabular}{|c|c|c|c|c|c|c|c|c|}
\hline No & Pertanyaan & STS & TS & c & $\mathbf{s}$ & ss & $\begin{array}{l}\text { Total } \\
\text { Skor }\end{array}$ & Jumlah \\
\hline 1 & $\begin{array}{l}\text { Website mudah } \\
\text { diakses dan } \\
\text { dioperasikan }\end{array}$ & 0 & 0 & 4 & 19 & 27 & 50 & 223 \\
\hline 2 & $\begin{array}{l}\text { Website memiliki } \\
\text { fasilitas interakgi } \\
\text { dengan petunjuk } \\
\text { yang jelas dan mudah } \\
\text { dipahami }\end{array}$ & 0 & 0 & 3 & 23 & 24 & 50 & 221 \\
\hline 3 & $\begin{array}{l}\text { Website memiliki } \\
\text { kelengkapan } \\
\text { informasi yang } \\
\text { memudahkan untuk } \\
\text { melakukan navigasi }\end{array}$ & 0 & 0 & 8 & 26 & 16 & 50 & 208 \\
\hline 4 & $\begin{array}{l}\text { Website memiliki } \\
\text { tautan halaman (link) } \\
\text { disetiap unit kerjanya }\end{array}$ & 0 & 0 & 9 & 23 & 18 & 50 & 209 \\
\hline 5 & $\begin{array}{l}\text { Website memiliki } \\
\text { tampilan yang } \\
\text { menarik (dari gegi } \\
\text { warna, gambar, } \\
\text { tulisan) }\end{array}$ & 0 & 0 & 4 & 18 & 28 & 50 & 224 \\
\hline 6 & $\begin{array}{l}\text { Website memberikan } \\
\text { pengalaman positif } \\
\text { (menambah } \\
\text { pengetahuan tentang } \\
\text { produk \& jasa } \\
\text { perusahaan) }\end{array}$ & 0 & 0 & 5 & 21 & 24 & 50 & 219 \\
\hline & TOTAL & 0 & 0 & 33 & 130 & 137 & 300 & 1304 \\
\hline
\end{tabular}

Untuk variabel Usability (X1) terdiri dari 6 item kuesioner dengan jumlah responden 50 orang, maka akan diperoleh kriteria berikut ini:

Skor aktual : 1304

Skor ideal : Bobot tertinggi X Jumlah kuesioner $\mathrm{X}$ Jumlah responden yakni $(5 \times 6 \times 50=1500)$

$$
\%=\quad \begin{gathered}
1304 \\
\frac{X 100 \%}{1500} \% \\
86,93 \%(\text { Sangat Baik })
\end{gathered}
$$

\section{Deskriptif Hasil Penelitian Variabel Information Quality (X2)}

\begin{tabular}{|c|c|c|c|c|c|c|c|c|}
\hline No & Pertanyaan & STS & TS & $\mathbf{C}$ & S & SS & $\begin{array}{l}\text { Total } \\
\text { Skor }\end{array}$ & Jumlah \\
\hline 1 & $\begin{array}{l}\text { Website ini menyediakan } \\
\text { informasi yang jelas (mudah } \\
\text { dipahami) dan akurat }\end{array}$ & 0 & 0 & 6 & 19 & 25 & 50 & 219 \\
\hline 2 & $\begin{array}{l}\text { Website ini menyediakan } \\
\text { informasi yang dapat } \\
\text { dipercaya }\end{array}$ & 0 & 0 & 4 & 19 & 27 & 50 & 223 \\
\hline 3 & $\begin{array}{l}\text { Website ini menyediakan } \\
\text { informasi yang mutakhir (up } \\
\text { to date) }\end{array}$ & 0 & 0 & 6 & 26 & 18 & 50 & 212 \\
\hline 4 & $\begin{array}{l}\text { Website ini menyediakan } \\
\text { informasi yang relevan } \\
\text { dengan barang \& jasa yang } \\
\text { ditawarkan }\end{array}$ & 0 & 0 & 9 & 21 & 20 & 50 & 211 \\
\hline 5 & $\begin{array}{l}\text { Website ini memiliki tingkat } \\
\text { rincian informasi yang } \\
\text { proporsional }\end{array}$ & 0 & 0 & 6 & 27 & 17 & 50 & 211 \\
\hline 6 & $\begin{array}{l}\text { Website ini menyediakan } \\
\text { informasi yang disajikan } \\
\text { dalam format yang sesuai } \\
\text { dann proporsional }\end{array}$ & 0 & 0 & 8 & 24 & 18 & 50 & 210 \\
\hline & TOTAL & 0 & 0 & 39 & 136 & 125 & 300 & 1286 \\
\hline
\end{tabular}

\section{Tabel 4.7 Hasil Penelitian Variabel Information Quality $\left(\mathrm{X}_{2}\right)$}

Untuk variabel Information Quality (X2) terdiri dari 6 item kuesioner dengan jumlah responden 50 orang, maka akan diperoleh kriteria berikut ini:

Skor aktual : 1286

Skor ideal : Bobot tertinggi X Jumlah kuesioner $\mathrm{X}$ Jumlah responden yakni $(5 \times 6 \times 50=1500)$

$$
\begin{array}{cc}
\%= & \frac{1286}{\times 100 \%} \% \\
= & 1500 \\
85,73 \%(\text { Sangat Baik })
\end{array}
$$

\section{Deskriptif Hasil Penelitian Variabel Service} Interaction Quality (X3)

\section{Tabel 4.8 Hasil Penelitian Variabel Service Interaction} Quality $\left(\mathbf{X}_{3}\right)$ 


\begin{tabular}{|c|c|c|c|c|c|c|c|c|}
\hline No & Pertanyaan & STS & TS & C & $\mathrm{s}$ & SS & $\begin{array}{l}\text { Total } \\
\text { Skor }\end{array}$ & Jumlah \\
\hline 1 & $\begin{array}{l}\text { Perusahaan pemilik website } \\
\text { mempunyai reputasi yang baik } \\
\text { (tidak berisi hal-hal yang } \\
\text { negative) }\end{array}$ & 0 & 0 & 4 & 19 & 27 & 50 & 223 \\
\hline 2 & $\begin{array}{l}\text { Perusahaan pemilik website } \\
\text { memberikan jaminan keamanan } \\
\text { jika saya melakukan transaksi }\end{array}$ & 0 & 0 & 4 & 15 & 31 & 50 & 227 \\
\hline 3 & $\begin{array}{l}\text { Perusahaan pemilik website } \\
\text { memberikan jaminan keamanan } \\
\text { data pribadi atau menjaga } \\
\text { privasi }\end{array}$ & 0 & 0 & 4 & 18 & 28 & 50 & 224 \\
\hline 4 & $\begin{array}{l}\text { Perusahaan pemilik website } \\
\text { mampu memnciptakan kesan } \\
\text { personal }\end{array}$ & 0 & 0 & 7 & 23 & 20 & 50 & 213 \\
\hline 5 & $\begin{array}{l}\text { Perusahaan pemilik website } \\
\text { mampu menciptakan nuansa } \\
\text { komunitas (kekeluargaan) }\end{array}$ & 1 & 1 & 10 & 25 & 13 & 50 & 198 \\
\hline 6 & $\begin{array}{l}\text { Perusahaan pemilik website } \\
\text { memberikan kemudahan untuk } \\
\text { menarik minat dan perhatian } \\
\text { nasabah }\end{array}$ & 1 & 0 & 11 & 22 & 16 & 50 & 202 \\
\hline & TOTAL & 2 & 1 & 40 & 122 & 135 & 300 & 1287 \\
\hline
\end{tabular}

Untuk variabel Service Interaction Quality (X3) terdiri dari 6 item kuesioner dengan jumlah responden 50 orang, maka akan diperoleh kriteria berikut ini:

Skor aktual : 1287

Skor ideal : Bobot tertinggi X Jumlah kuesioner

$\mathrm{X}$ Jumlah responden

yakni $(5 \times 6 \times 50=1500)$

$$
\%=\frac{1287}{1500}
$$

$=85,8 \%($ Sangat Baik $)$

4. Deskriptif Hasil Penelitian Variabel Service User Satisfication (Y)

Tabel 4.9 Hasil Penelitian Variabel Service User

Satisfication (Y)

\begin{tabular}{|r|l|r|r|r|r|r|r|r|}
\hline No & \multicolumn{1}{|c|}{ Pertanyaan } & STS & TS & C & S & SS & $\begin{array}{r}\text { Total } \\
\text { Skor }\end{array}$ & Jumlah \\
\hline 1 & $\begin{array}{l}\text { Website ini ternyata dapat } \\
\text { diakses dan dinavigasi dengan } \\
\text { mudah tanpa ada masalah }\end{array}$ & 0 & 0 & 12 & 20 & 18 & 50 & 206 \\
\hline 2 & $\begin{array}{l}\text { Website ini menyediakan semua } \\
\text { informasi yang saya butuhkan }\end{array}$ & 0 & 0 & 11 & 20 & 19 & 50 & 208 \\
\hline & $\begin{array}{l}\text { Website ini sangat bermanfaat } \\
\text { bagi saya, keputusan untuk } \\
\text { mengakses dan memanfaatkan } \\
\text { website ini }\end{array}$ & & & & & & & \\
\hline \multicolumn{1}{|c|}{ TOTAL } & $\mathbf{0}$ & $\mathbf{0}$ & $\mathbf{2 8}$ & $\mathbf{6 3}$ & $\mathbf{5 9}$ & $\mathbf{1 5 0}$ & $\mathbf{6 3 1}$ \\
\hline
\end{tabular}

Untuk variabel Service User Satisfication (Y) terdiri dari 3 item kuesioner dengan jumlah responden 50 orang, maka akan diperoleh kriteria berikut ini:

Skor aktual : 631

Skor ideal : Bobot tertinggi X Jumlah kuesioner

$\mathrm{X}$ Jumlah responden

yakni $(5 \times 3 \times 50=750)$

631

$\%=$

750

$=84,13 \%($ Sangat Baik $)$

\subsection{Kesimpulan Hasil Penelitian}

Dari hasil penelitian berdasarkan usability (ketergunaan), information quality (kualitas informasi), service interaction quality (kualitas informasi layanan), dan service user satisfication (kepuasan nasabah) diperoleh hasil penilaian sebagai berikut :

\section{Tabel 4.14 Kesimpulan Hasil Penelitian}

\begin{tabular}{|l|c|c|}
\hline \multicolumn{1}{|c|}{ Variabel } & Hasil Penelitian & Keterangan \\
\hline Usability & $86,93 \%$ & Sangat Baik \\
\hline Information Quality & $85,73 \%$ & Sangat Baik \\
\hline $\begin{array}{l}\text { Serviice Interaction } \\
\text { Quality }\end{array}$ & $85,8 \%$ & Sangat Baik \\
\hline Service User Satisfication & $84,13 \%$ & Sangat Baik \\
\hline Total & & 342,59 \\
\hline Rata-rata & \multicolumn{2}{|c}{$85,6475 \%$} \\
\hline Kesimpulan & \multicolumn{2}{|c}{ Sangat Baik } \\
\hline
\end{tabular}

Dengan hasil penelitain di atas dapat ditarik kesimpulan kondisi saat ini rata-rata adalah sudah Sangat Baik, namun ratarata nilai masih pada angka $85,6475 \%$. Sedangkan yang ditargetkan pada tahun 2021 adalah rata-rata berada pada nilai $90 \%$ sehingga terdapat nilai gap dengan penjelasan sebagai berikut :

Tabel 4.15 Analisis Nilai Gap Hasil Penelitian Terhadap Target

\begin{tabular}{|l|c|c|c|}
\hline \multicolumn{1}{|c|}{ Variabel } & Target Tahun 2021 & Hasil Penelitian & Gap \\
\hline Usability & $90 \%$ & $86,93 \%$ & $3,07 \%$ \\
\hline Information & $90 \%$ & $85,73 \%$ & $4,27 \%$ \\
\hline Serviice Interaction & Chart Area $90 \%$ & $85,8 \%$ & $4,2 \%$ \\
Quality & $90 \%$ & $84,13 \%$ & $5,87 \%$ \\
\hline Service User & & & \\
Satisfication & & & \\
\hline
\end{tabular}


Berikut adalah diagram radar berdasarkan tabel 4.15

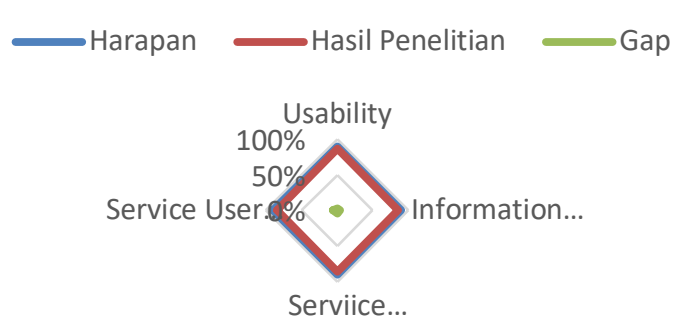

\section{Gambar 4.6 Diagram Radar Nilai Gap Hasil Penelitian Terhadap Target}

Berdasarkan hasil analisis yang didapatkan, setiap komponen variabel memang sudah di tingkat sangat baik. Namun jika dibandingkan dengan harapan untuk kedepannya masih perlu ditingkatkan. Terutama di variabel Service User Satisfication (Kepuasan Nasabah) terhadap website Bank Sinarmas. Bentuk peningkatannya dapat berupa memeperbarui secara berkala fitur yang terdapat dalam website sehingga meminimalisir error pada saat digunakan oleh nasabah.

\section{IV.PENUTUP}

\subsection{Kesimpulan}

Dapat diambil kesimpulan dari penelitian ini bahwa penerapan metode webqual 4.0 terhadap pengaruh kualitas website terhadap kepuasan nasabah sangat berdampak untuk lebih meningkatkan kualitas website di PT Bank Sinarmas Tbk. Berikut terdapat beberapa kesimpulan persen skor yang didapat:

1. Ketergunaan website (Usability) sebesar $86,93 \%$ dengan nilai sangat baik.

2. Kualitas informasi pada website (Information Quality) sebesar $85,73 \%$ dengan nilai sangat baik.

3. Kualitas informasi layanan (Service Interaction Quality) sebesar $85,8 \%$ dengan nilai sangat baik.

4. Kepuasan Nasabah (Service User Satisfication) sebesar $84,13 \%$ dengan nilai sangat baik.

5. Hasil dari hipotesa ialah kualitas website dengan metode webqual 4.0 berpengaruh positif terhadap kepuasan nasabah PT Bank Sinarmas Tbk dengan total keseluruhan mendapatkan nilai sangat baik.

\subsection{Saran}

Berdasarkan pada kesimpulan di atas, berikut ini merupakan saran yang dapat dijadikan bahan pertimbangan untuk meningkatkan kualitas website di PT Bank Sinarmas Tbk

1. Berdasarkan hasil analisis yang didapatkan, setiap komponen variabel memang sudah di tingkat sangat baik. Namun jika dibandingkan dengan harapan untuk kedepannya masih perlu ditingkatkan. Terutama di variabel Service User Satisfication (Kepuasan Nasabah) terhadap website Bank Sinarmas. Bentuk peningkatannya

dapat berupa memeperbarui secara berkala fitur yang terdapat dalam website sehingga meminimalisir error pada saat digunakan oleh nasabah.

2. Dari hasil analisis secara keseluruhan, kualitas website pada PT Bank Sinarmas Tbk masih belum mencapai target yang ditentukan, maka dihimbau agar dilakukannya pembaharuan secara berkala dan menjaga agar terhindar dari error.

\section{DAFTAR PUSTAKA}

[1]

[2]
Arikunto, S., \& Jabar. Evaluasi Program Pendidikan. 2004, Jakarta: Bumi Aksara.

Budi Sutedjo Dharma Oetomo, S.Kom., MM, Pengantar Teknologi Informasi Internet Konsep dan Aplikasi, Andi, Yogyakarta,

Cangelosi, S. J., Merancang Tes Untuk Menilai Prestasi Siswa. Bandung: ITB.

Christiana. Analisis Pengaruh Kualitas Pelayanan Terhadap Kepuasan Nasabah, 2012. Semarang.

Dr. Lantip Diat Prasojo, Riyanto. S.kom. Teknologi Informasi Pendidikan, Gava Media, 2011, Yogyakarta Ghozali, Imam. 2009. “Aplikasi Analisis Multivariate dengan Program SPSS “. Semarang : UNDIP.

Kadir, Abdul, Pengenalan Sistem Informasi, Andi, 2003, Yogyakarta

Kapoun, J, Teaching Undergrads WEB Evaluation: A Guide for Library Instruction. College \& Research Libraries News, [t.th], Hal. 522-523

Kasmir, S.E., M.M, Manajemen Perbankan, PT. Raja Grafindo Persada, Jakarta, hal, 11-13

Napitupulu, D. 2017 Analysis of Factors Affecting Website Quality Based on Webqual Aprroach (Study case:XYZ University), Advanced Science Engineering Information Technolgy, 792.

Setiawan, N. 2007. Penentuan ukuran sampel memakai rumus slovin dan tabelkrejcie-morgan: telaah konsep dan aplikasinya. Makalah disampaikan pada Diskusi Ilmiah Jurusan Sosial Ekonomi Fakultas Peternakan Unpad, Bandung.

Suharsimi, Arikunto. 2006. Prosedur Penelitian: Suatu Pendekatan Praktek. Jakarta: Rineka Cipta.

Sudjarwo, Manajemen Penelitian Sosial. Mandar Maju. 2009. Bandung

Sutabri, Tata, Analisa Sistem Informasi, Andi, Ed.1, 2004, Yogyakarta

Sutabri, Tata, Sistem Informasi Manajemen, Andi, 2007, Yogyakarta

Stanislaus S. Uyanto, Ph.D.,Pedoman Analisis Data dengan SPSS. Graha Ilmu. 2009. Jakarta

Zonanesia. 2016. Jenis - jenis bank dan fungsinya. https://www.niagahoster.co.id/blog/jenis-website/ https://www.kamusq.com/2013/04/analisa-adalahdefinisi-dan-arti-kata.html 
Bangkit Indonesia, Vol. IX, No.01, Bulan Maret 2020

http://catur.dosen.akprind.ac.id/2010/09/01/menguku r-kualitas-website-dan-layanan-ti/

[21] https://www.statistikian.com/spss 